\title{
Supported metal catalysts at the single-atom limit - A viewpoint
}

\author{
Maria Flytzani-Stephanopoulos * \\ Department of Chemical and Biological Engineering, Tufts University, Medford, MA, USA
}

\section{A R T I C L E I N F}

\section{Article history:}

Received 1 June 2017

Accepted 9 July 2017

Published 5 September 2017

\section{Keywords:}

Single atom alloys

Gold

Palladium

Supported single atom catalysts

Water-gas shift

Methanol steam reforming

Ethanol dehydrogenation

Butadiene hydrogenation

\begin{abstract}
A B S T R A C T
An account of recent work on supported single-atom catalyst design is given here for reactions as diverse as the low-temperature water-gas shift, methanol steam reforming, selective ethanol dehydrogenation, and selective hydrogenation of alkynes and dienes. It is of fundamental interest to investigate the intrinsic activity and selectivity of the active metal atom site and compare them to the properties of the corresponding metal nanoparticles and sub-nm clusters. It is also important to understand what constitutes a stable active metal atom site in the various reaction environments, and maximize their loadings to allow us to design robust catalysts for industrial applications. Combined activity and stability studies, ideally following the evolution of the active site as a function of catalyst treatment in real time are recommended. Advanced characterization methods with atomic resolution will play a key role here and will be used to guide the design of new catalysts.
\end{abstract}

(C) 2017, Dalian Institute of Chemical Physics, Chinese Academy of Sciences. Published by Elsevier B.V. All rights reserved.

\section{Introduction}

During the past fifteen years, reports of catalytic activity and unique selectivity of supported metals at the single-atom limit have sparked the interest of the catalysis research community, and many reactions have now been examined or are under investigation using single metal atoms coordinated and stabilized on various supports. The support may be a zeolite or an open support, such as the surface of an oxide or carbon with which the atoms stably coordinate through $-\mathrm{O},-\mathrm{N},-\mathrm{Cl}$, or other linkages. The case of a metal atom embedded stably in the surface of another metal is that of single-atom alloys. When the metal atom is coordinated to a support with -0 linkages, it is in essence a cation. At metal loadings higher than $\sim 1 \mathrm{wt} . \%$, metal nanoparticles, sub-nanometer clusters, and isolated metal atoms anchored on specific sites of the support can all be present on the surface. With the recent advances of atomic-resolution microscopy, the dispersed metal atoms, whether isolated or present as dimers, trimers, or sub-nm clusters, have been clearly imaged, and in some cases their evolution under reaction conditions has been documented and correlated to their reactivity. These developments will ultimately uncover the extent of "strong metal-support interaction" which has been freely used to describe intractable by current techniques but measurable catalytic effects at the interfaces between metal nanoparticles and supports. Thus, mechanistic elucidation and understanding of reaction pathways will be the first benefit realized by the design of single-atom metal catalysts. The second, and equally important benefit will be the development of $100 \%$ efficient and more cost-effective catalysts, using only a fraction of the noble metals currently in use, without compromising activity, and often by improving selectivity and yields of the desired products. The ultimate beneficiary will be the public, that is all of us, who will

\footnotetext{
* Corresponding author. E-mail: maria.flytzani-stephanopoulos@tufts.edu DOI: 10.1016/S1872-2067(17)62886-9 | http://www.sciencedirect.com/science/journal/18722067 | Chin. J. Catal., Vol. 38, No. 9, September 2017
} 
enjoy products with smaller carbon footprint by adopting new, greener and more energy-efficient processes for fuels and chemicals production.

While there are still significant challenges associated with the synthesis and characterization of single metal atoms on various supports, progress has been made on the synthesis side that allows designs of exclusively atomic distributions of the metal, which may then be characterized unambiguously. These developments are necessary to inform the debate regarding the reactivity of the supported single metal atoms. For some reactions, the atoms will be the active sites over the whole range of the operating parameters, while for others, deactivation will take place or a different pathway will open upon evolution of the atomic sites into metal clusters. The dynamics of structural evolution and their correlation to reactivity are currently poorly understood. Yet, for a practical catalyst, metal loadings of order $1 \mathrm{wt} . \%$ are desirable. How can one achieve this and still retain atom stability?

Looking back at the work that began in our lab more than twenty years ago on gold and copper oxidation catalysts dispersed on ceria supports [1,2], we can trace the evolution in our understanding of the nature of the active site, first in ceria and then on other oxide supports. Defect-rich ceria is an excellent metal dispersant, and as such it has been used by the automotive industry to disperse and stabilize the Pt group metals to the atomic state in the designs of the three-way catalysts for exhaust gas treatment [3]. The high oxygen storage capacity of ceria in fast redox operation of the catalytic converter helps to keep the active site atomic and oxidized Pt- $\mathrm{O}^{-}$[3]. We first reported similar atomic sites for gold and platinum supported on ceria and demonstrated them as the exclusive active sites for the water-gas shift reaction in 2003 [4]. The atomic $\mathrm{Au}-\mathrm{O}_{x^{-}}$and Pt- $\mathrm{O}_{x^{-}}$sites were not identified by atomic-resolution imaging, which was not accessible at the time, but by removing all other metal structures (nanoparticles, clusters) from ceria by leaching techniques and using spectroscopic methods to characterize the residual active metal phase [4-7]. Interestingly, for this reaction, the active atom sites operate independent of the presence of the other metal structures $[4,5]$. Hence, while good catalyst designs should focus on maximizing the number of the active metal atom sites, the presence of other metal structures on the surface is not detrimental to the water-gas shift (WGS) reaction. This may of course be different for selective oxidation or hydrogenation reactions, where the selectivity may be adversely affected by the presence of extended metal surfaces, such as in metal nanoparticles.

Over the past decade, reports identifying isolated metal atom-species on supports as the active sites for certain reactions have enriched the relevant literature. Arguably, the most valuable development has been atomic and even sub-atomic resolution imaging techniques, especially the aberration corrected high angle annular dark field scanning transmission microscopy (ac-HAADF/STEM). With sub-Ångstrom resolution, isolated metal atoms and cations stabilized by $-\mathrm{O}$ or other atoms on supports have been imaged and their evolution as a function of treatment followed in real time [8]. Several reactions have now been documented as occurring on single metal atom sites. In this account, a few such reactions are illustrated, including reactions of interest to hydrogen production and to the selective hydrogenation of butadiene to butenes, which takes place on a new type of catalyst, the single-atom alloys, comprising single atoms of one metal embedded in the surface lattice of another metal. A variety of open supports are considered, which often act as mere carriers of the active metal atom site, without participating in the reaction pathway. On the other hand, a strong electronic effect from the support has been reported for some reactions occurring on metal cations on a zeolite support, the latter serving as a ligand to the metal cation anchored on extra-framework -0 , as exemplified in the extensive work of Bruce Gates on molecular catalyst designs over the past two decades.

\section{Examples of reactions catalyzed by single-atom metal sites on "active' and "inert" supports}

\subsection{WGS reaction}

We begin here by an account of the WGS reaction which has been established over the years to take place on single $\mathrm{M}-\mathrm{O}_{x^{-}}$ species on a reducible oxide support like ceria [4-7], iron oxide [7,8], titania [9-12], and others. Nanoparticles of the metal $\mathrm{M}(\mathrm{Pt}, \mathrm{Au}, \mathrm{Cu}$, etc.) do not catalyze the WGS reaction, except at their interfacial (basal, peripheral) sites with the support, which are cationic. Hence, a lot of metal can be saved by not preparing the catalyst in nanoparticle form in the first place. Of course, the WGS reaction does take place on single crystals, e.g. $\mathrm{Cu}(111)$ or $\mathrm{Pt}(111)$, but at a much lower rate. The $\mathrm{M}-\mathrm{O}_{\mathrm{x}} \mathrm{-S}$ site, where $\mathrm{S}$ is the cation of the support oxide, catalyzes the dissociation of $\mathrm{H}_{2} \mathrm{O}$, the onset of which is facilitated (often by several hundred degrees) by the presence of the $\mathrm{M}-\mathrm{O}_{X^{-}}$ species. However, once regenerable $-\mathrm{OH}$ groups are formed proximal to $\mathrm{CO}$ adsorbed on the $\mathrm{M}-\mathrm{O}_{x^{-}}$species, the identity of the "supplier support" is lost. Hence, it has been realized that the support effect is "indirect", as shown in Fig. 1 for the WGS turnover frequencies on atomically dispersed $\mathrm{Pt}-\mathrm{O}_{x^{-}}$and $\mathrm{Au}-\mathrm{O}_{x^{-}}$ species on various supports [4-13], including irreducible ones, as will be discussed below. The TOF values are the same whether the metal atom is supported on $\mathrm{CeO}_{2}, \mathrm{Fe}_{2} \mathrm{O}_{3}$, or $\mathrm{TiO}_{2}$, etc. As expected, the TOF varies with the identity of the metal atom, Fig. 1(A) and (B). Thus, the key reaction step is:

$\mathrm{COM}_{-\mathrm{O} x-}+\mathrm{S}-\mathrm{OH} \rightarrow-\mathrm{COOH}_{\mathrm{M}-\mathrm{Ox}-}+\mathrm{S}$ -

$\mathrm{CO}_{2}$ and $\mathrm{H}_{2}$ are desorbed in following steps while the metal cation may undergo a redox from a higher to a lower oxidation state during the reaction. Further evidence that the support effect is indirect has been garnered by using "inert" oxide supports that cannot dissociate $\mathrm{H}_{2} \mathrm{O}$ at low temperatures $\left(\sim 100^{\circ} \mathrm{C}\right)$ even in the presence of a metal. In this case, addition of alkali ions to stabilize the $\mathrm{M}-\mathrm{O}_{x^{-}}$- species has been successfully applied. We may think of the alkali cations as equivalent to $\mathrm{Ce}^{4+}$, $\mathrm{Fe}^{3+}$, etc. providing $-\mathrm{OH}$ to the adsorbed $\mathrm{CO}$. The alkali ions are 


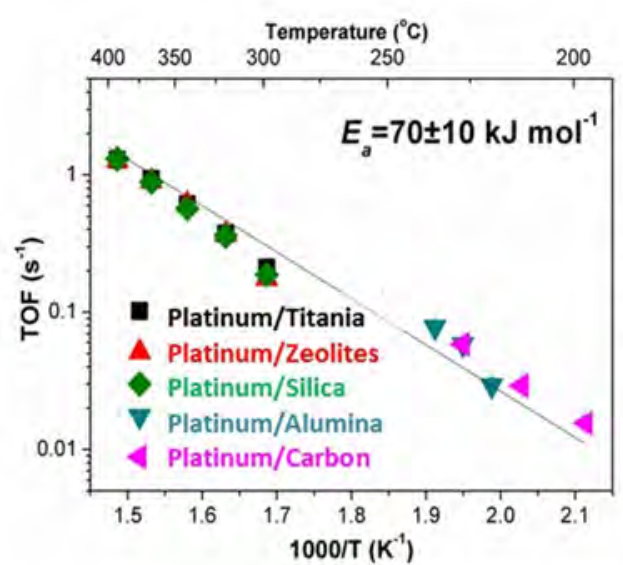

(A)

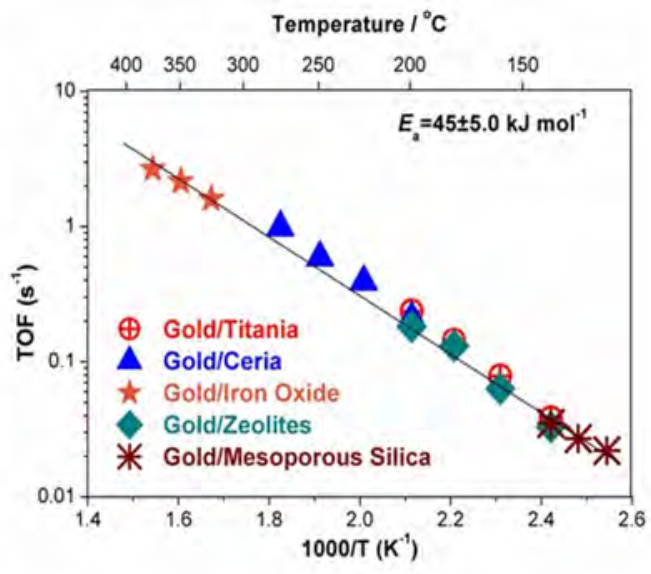

(B)

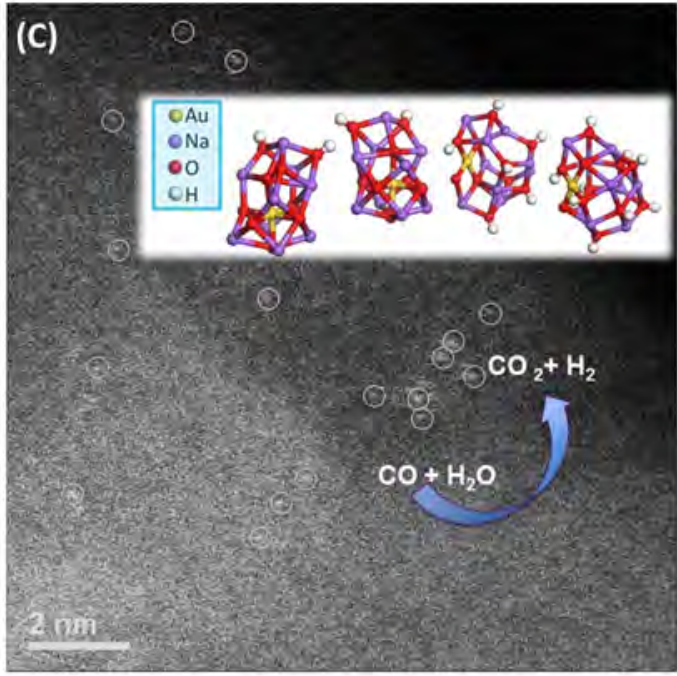

Fig. 1. (A) TOF of the WGS reaction on atomic Pt- $\mathrm{O}_{x}(\mathrm{OH})$-Na catalysts on various inert supports in a simulated reformate-gas mixture $(11 \%$ CO-26\% $\mathrm{H}_{2} \mathrm{O}-7 \% \mathrm{CO}_{2}-26 \% \mathrm{H}_{2}-\mathrm{He}$ ); (B) TOF plot for the WGS reaction over single atom gold catalysts on various active and inert supports, in the same simulated reformate-type gas mixture. The active gold sites are structurally similar $\left(\mathrm{Au}-\mathrm{O}(\mathrm{OH})_{x^{-}}\right)$on any support, with similar WGS reaction activity; (C) Aberration-corrected HAADF/STEM image of the $0.25 \mathrm{Au}-\mathrm{Na} /[\mathrm{Si}] \mathrm{MCM} 41$ catalyst. The circles are drawn around isolated gold atoms. The inset shows a few potential structures of the -O-Na stabilized single-atom gold-centered clusters by density functional theory (DFT) calculations. Adapted from Ref. [4-13].

themselves stabilized in a coordination sphere around the metal atom through -0 linkages. Oxo clusters of the formula $\mathrm{M}-\mathrm{O}_{x}-(\mathrm{OH}) y-\mathrm{Na} x$ are representations of the thus stabilized single metal atom. These can adsorb weakly on any support, including titania, zeolites, $m-\mathrm{SiO}_{2}, \mathrm{Al}_{2} \mathrm{O}_{3}$ [9-12], carbon nanotubes [13], etc. Any extra amount of alkali is easily washed away from the surface of the support, but the amount coordinated with the active metal ion remains intact upon washing. The atomic ratio $\mathrm{M} / \mathrm{Na}$ is $\sim 1 / 10$ in these clusters. Ab-initio Molecular Dynamics has been used to predict various such structures for both $\mathrm{Pt}$ and $\mathrm{Au}$. Once coordinated with alkali ions through -O linkages, the metal atom center is stabilized, Fig. 1(C). The TOF of the atomic $\mathrm{Au}$ or Pt in the oxo clusters is the same on all the inert supports, and is the same as that on active supports where no alkali additive is used, Fig. 1 . The clusters remain intact up to 200 or $350{ }^{\circ} \mathrm{C}$ respectively, for $\mathrm{Au}$ [11] and Pt [12], under realistic WGS conditions. The catalytic properties of these clusters for other reactions catalyzed by gold or platinum are presently under investigation. In general, they may present a strategy for applying them stably on various supports via a simple preparation method.

\subsection{Methanol steam reforming (SRM) reaction}

The SRM is an important reaction for the production of hydrogen at low temperatures for use in proton exchange membrane (PEM) fuel cells. The $\mathrm{Cu} / \mathrm{ZnO}$ catalysts which are active for methanol synthesis, are also active for the SRM reaction. The catalytic reaction on $\mathrm{Cu}$ occurs through the direct dehydrogenation of methanol to $\mathrm{CO}_{2}$ and $\mathrm{H}_{2}$, thus it is not limited by the WGS reaction equilibrium, as no $\mathrm{CO}$ is produced in the process. In studies of supported $\mathrm{Au} / \mathrm{CeO}_{2}$ catalysts, our group was first to report that catalysis of the SRM reaction by gold was similar to that of copper. Hence, supported gold catalysts could be developed as a more robust alternative to copper, for applications such as fuel processing for fuel cells 

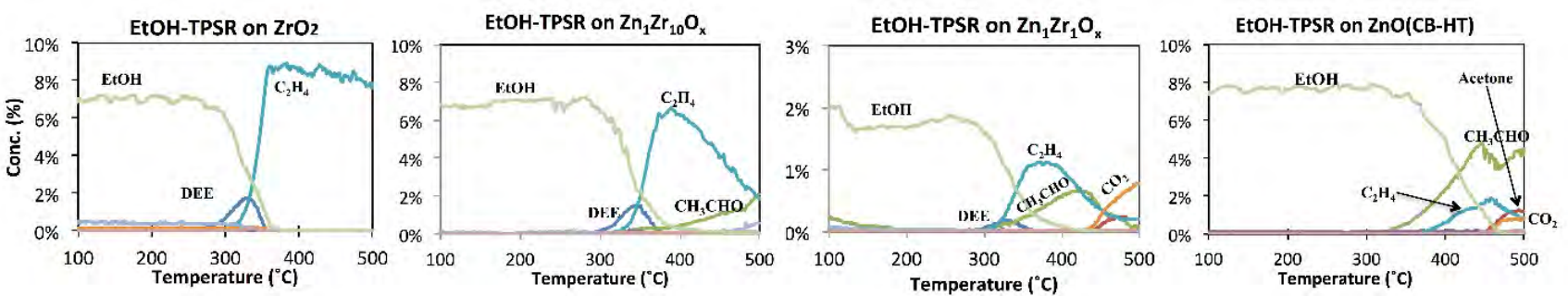

Fig. 2. Ethanol dehydrogenation over $\mathrm{ZrO}_{2}, \mathrm{ZnO}$ and their mixed oxides. Gas mixture: $8 \% \mathrm{EtOH}, 92 \% \mathrm{He}$, flowrate $=50 \mathrm{~mL} / \mathrm{min}$; linear temperature ramp from $30-500{ }^{\circ} \mathrm{C}$ in $4 \mathrm{~h} ; 100 \mathrm{mg}$ catalyst; $\mathrm{WHSV}=4.46 \mathrm{~g}_{\mathrm{EtoH}} /\left(\mathrm{g}_{\text {cat }} \cdot \mathrm{h}\right)$. In panel 3, 2\% EtOH was used. Adapted from Ref. [20].

where the $\mathrm{Cu} / \mathrm{ZnO}$ catalyst is unstable to air exposure and to cyclic shut down/restart operation in full gas streams. The key step in the reaction mechanism is the formation of the ester, methyl formate, though the self-coupling of methanol (via methoxy and formaldehyde intermediates) [14,15]. In the presence of $\mathrm{H}_{2} \mathrm{O}$, methyl formate is hydrolyzed to formic acid, which dehydrogenates to $\mathrm{CO}_{2}$ and $\mathrm{H}_{2}$ on $\mathrm{Au}-\mathrm{O}_{x^{-}}$catalysts. Hence, no $\mathrm{CO}$ is formed in the process, and the $\mathrm{Au} / \mathrm{CeO}_{2}$ catalyst is $100 \%$ selective to $\mathrm{CO}_{2}$ and $\mathrm{H}_{2}$. Further work on $\mathrm{Au} / \mathrm{ZnO}$ has revealed that the kinetics of the SRM reaction on gold are the same whether ceria or zinc oxide is used as support [16]. And they were the same on a mixed oxide support, $\mathrm{ZnO}-\mathrm{ZrO}_{2}$ [17]. The acidity of the support was not important at low temperatures, where the chemistry of $\mathrm{Au}$ was exclusively observed. The atomic $\mathrm{Au}-\mathrm{O}_{x^{-}}$species was identified as the sole catalytic active site. The confirmation came from a study of 1 wt.\% $\mathrm{Au} / \mathrm{CeO}_{2}$ nanorods (mostly [110] surfaces) from which the nanoparticles and sub-nm clusters of gold were leached away by cyanidation and the remaining $0.5 \mathrm{wt} . \% \mathrm{Au}$ (cations) on ceria, was equally active (per gram catalyst) as the parent $[14,15]$. On the other hand, 1 wt.\% Au on ceria nanocubes ([100] surfaces), was present mostly as $3 \mathrm{~nm}$-size gold nanoparticles due to the lack of enough anchoring sites for gold on these surfaces, and had very low activity compared to the gold on the ceria nanorods. As found after cyanidation, which left only $0.03 \mathrm{wt} . \% \mathrm{Au}$ on the cube surfaces, the low (per gram catalyst) activity matched the little amount of residual gold, present as isolated cations on the ceria surface, and was equal to the low activity measured for the parent catalyst. Hence, similar to WGS, the SRM reaction is catalyzed by single atomic $\mathrm{Au}-\mathrm{O}_{x^{-}}$species, anchored on the support, the latter not participating directly in the reaction mechanism. It is noteworthy that the identified mechanism (through methyl formate) of the SRM reaction on supported gold atoms on ceria or zinc oxide is the same as for the partial oxidation of methanol producing methyl formate and water, reported both on oxygen-activated $\mathrm{Au}[111]$ surfaces in vacuum[18] and in catalytic studies on nanoporous $\mathrm{Au}$ (doped with $\mathrm{Ag}$ atoms) under 1 bar pressure [19]. In all cases, the oxidized $\mathrm{Au}-\mathrm{O}_{x^{-}}$ species are the active sites for the oxidative dehydrogenation and the self-coupling of methanol. The -0 supplier, $\mathrm{AgO}_{x}, \mathrm{CeO}_{x}$, $\mathrm{FeO}_{x}$, etc. is not part of the reaction mechanism.

\subsection{Ethanol dehydrogenation reaction}

In recent work, we reported that the $\mathrm{ZnZrO}_{x}$ composite oxide was a superior support for gold compared to either of the single oxides $\mathrm{ZnO}$ or $\mathrm{ZrO}_{2}$ [17], better dispersing and anchoring the atomic $\mathrm{Au}-\mathrm{O}_{x^{-}}$species needed to catalyze the methanol steam reforming reaction selectively to $\mathrm{H}_{2}$ and $\mathrm{CO}_{2}$. This was followed by a report that the same species catalyze the selective dehydrogenation of ethanol to acetaldehyde and $\mathrm{H}_{2}$ at moderate temperatures [20]. Catalytic conversion of ethanol to targeted chemicals, like acetaldehyde and acetone, usually takes place in a cascade of reactions, where the nature of the catalyst plays an essential role in the reaction pathway.

Bare $\mathrm{ZnZrO}_{x}$ oxides activate the ethanol conversion at $\sim 300^{\circ} \mathrm{C}$ (Fig. 2). Strong Lewis acidic sites on pure $\mathrm{ZrO}_{2}$, whose occurrence is proved by pyridine-IR tests, primarily catalyze the dehydration of ethanol to produce ethylene. With increased $\mathrm{ZnO}$ loading, production of ethylene monotonically decreases as the dispersed $\mathrm{ZnO}$ clusters in the domain of $\mathrm{ZrO}_{2}$ moderate the acidity of the $\mathrm{ZnZrO}_{x}$ mixture. One drawback of the bare $\mathrm{ZnZrO}_{x}$ composite oxide for ethanol dehydrogenation is that the temperature windows for the ethylene and acetaldehyde production mostly overlap, so that separation of the products would be an issue for practical applications [20].

Addition of $1 \mathrm{wt} . \%$ Au to the bare mixed oxide supports by the anion adsorption method significantly changes the product distribution in the temperature range of $200-400{ }^{\circ} \mathrm{C}$ (Fig. 3(a)) [20]. Well dispersed $\mathrm{Au}$ on $\mathrm{Zn}_{1} \mathrm{Zr}_{10} \mathrm{O}_{x}$ and $\mathrm{Zn}_{1} \mathrm{Zr}_{1} \mathrm{O}_{x}$ activate the ethanol dehydrogenation at a temperature as low as $\sim 200{ }^{\circ} \mathrm{C}$, while on pure $\mathrm{ZrO}_{2}$ and $\mathrm{ZnO}$ the light-off temperature is shifted to $\sim 300{ }^{\circ} \mathrm{C}$. As gold selectively catalyzes the dehydrogenation of ethanol at low-temperatures, a wide temperature window is now found between the production of acetaldehyde and ethylene, which can be exploited for the industrial application of this type of catalyst. The reaction takes place similarly with or without water added to the feed stream. Production of another valuable chemical, acetone, from acetaldehyde, was activated at intermediate temperatures before ethylene was produced at high temperature $\left(\geq 450^{\circ} \mathrm{C}\right)$. Cyanidation of parent catalysts and imaging of the leached derivatives identified the active site as the isolated single atoms of gold anchored on specific sites of the composite oxide surfaces, Fig. 3(b).

\subsection{Reactions on single metal atoms coordinated with $-\mathrm{Cl},-\mathrm{N}$, or another metal}

The coordination of a metal atom with atoms other than -0 on supports is of interest for other reactions, especially selective hydrogenations. In this brief account, illustrative, but 

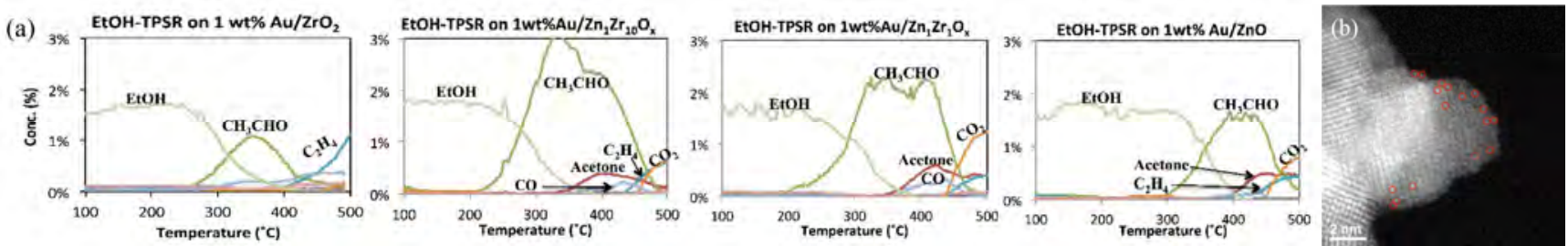

Fig. 3. (a) Dehydrogenation of ethanol to well-separated acetaldehyde from ethylene on Au. Gas mixture: $2 \% \mathrm{EtOH}, 98 \% \mathrm{He}=50 \mathrm{~mL} / \mathrm{min}$, linear temperature ramp from $30-500{ }^{\circ} \mathrm{C}$ in $4 \mathrm{~h} ; 100 \mathrm{mg}$ catalyst; WHSV $=111.5 \mathrm{~g}_{\text {EtoH }} /\left(\mathrm{g}_{\mathrm{Au}} \cdot \mathrm{h}\right)$; (b) ac-HAADF-STEM of the leached $1 \mathrm{wt} . \% \mathrm{Au} / \mathrm{Zn}_{1} \mathrm{Zr}_{10} \mathrm{O}_{x}$ shows that the residual gold after leaching is solely in the form of isolated $\mathrm{Au}$ atoms. $\mathrm{NaCN}$ leaching of $1 \mathrm{wt} . \% \mathrm{Au} / \mathrm{Zn}_{1} \mathrm{Zr}_{10} \mathrm{O}_{x}$ for 5 min removes $42 \%$ of the gold and $\sim 5 \%$ of the $\mathrm{Zn}$ from the support. Adapted from Ref. [20].

not all inclusive, examples from the recent literature are mentioned, and the interested reader is prompted to explore the literature for additional examples. Single $\mathrm{Au}(\mathrm{I})$ cations have been recently identified as the active sites for the $\mathrm{Au} / \mathrm{Carbon}$ catalyst for the selective hydrochlorination of acetylene to produce the vinyl chloride monomer, VCM, used to make PVC, one of the world's most ubiquitous plastics [21]. The new catalyst, pioneered by Hutchings, is commercialized in China to replace the soon- to- be- banned highly toxic mercuric chloride catalyst. The gold cations are stabilized by - $\mathrm{Cl}$ linkages, and a redox between $\mathrm{Au}(\mathrm{I})$ and $\mathrm{Au}(\mathrm{III})$ appears to operate on the active catalyst. Carbons with a large number of anchoring sites should be used to achieve 1 wt.\% Au active sites (Fig. 4(a)).

In another example, using Pd single atoms, anchoring the Pd atoms onto a mesoporous polymerized graphitic carbon nitride, mpg- $\mathrm{C}_{3} \mathrm{~N}_{4}$, coordination with $-\mathrm{N}$ atoms and the ensuing

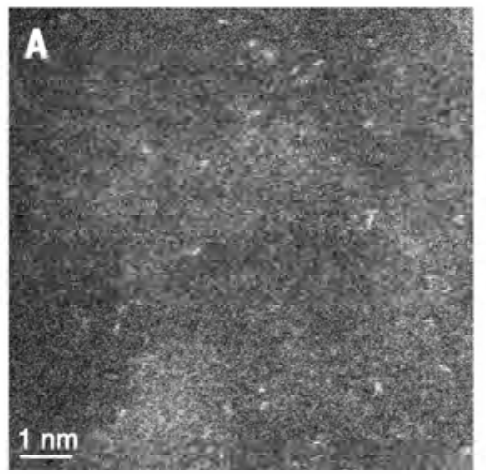

(a)

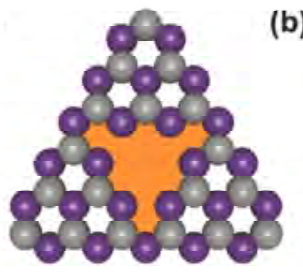

(b)

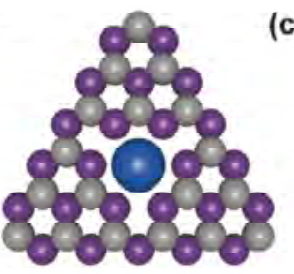

(c)

\section{B}
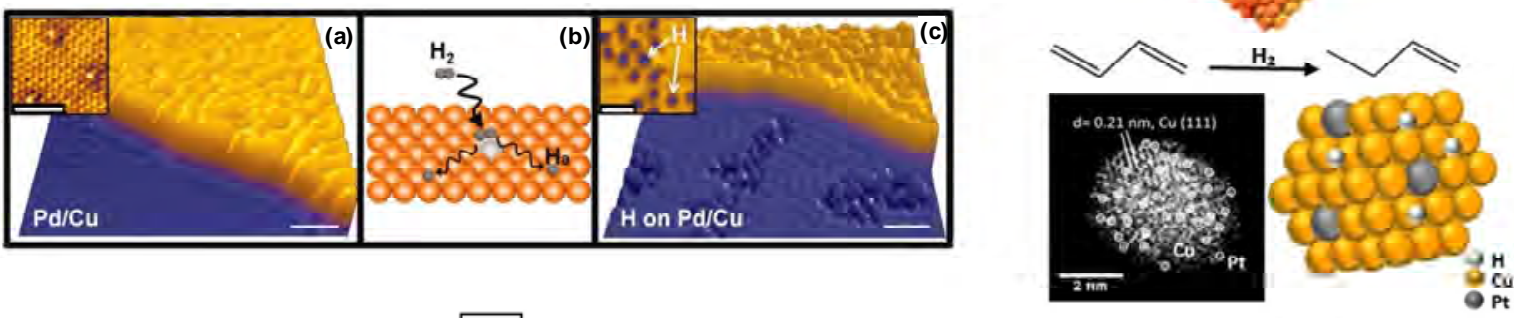

C

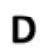

Fig. 4. (A) Au/C: single-site isolated gold catalysts in acetylene hydrochlorination; (B) Single Pd atom on $\mathrm{C}_{3} \mathrm{~N}_{4}$ in a 6-fold cavity catalyzes the selective hydrogenation of 1-hexyne to 1-hexene at close to ambient conditions; (C) STM images showing atomically dispersed Pd atoms in a Cu(111) surface and hydrogen dissociation on the Pd atoms and spillover onto the $\mathrm{Cu}$ surface. (a) Pd alloys preferentially above the step edges of a $\mathrm{Cu}(111)$ surface as evidenced by the rumpled appearance of the upper terrace (scale bar $5 \mathrm{~nm}$ ). Inset: atomic resolution of the $\mathrm{Cu} / \mathrm{Pd}$ alloy on the upper terrace showing individual, isolated Pd atoms in the surface layer appearing as protrusions (scale bar $2 \mathrm{~nm}$ ); (b) Schematic showing $\mathrm{H}_{2}$ dissociation and spillover at individual, isolated Pd atom sites in the $\mathrm{Cu}$ surface. (c) Islands of $\mathrm{H}$ atoms imaged after hydrogen uptake appear as depressed regions on the clean $\mathrm{Cu}(111)$ lower terrace (scale bar $5 \mathrm{~nm}$ ). Inset: high-resolution image of individual hydrogen atoms on $\mathrm{Cu}(111)$ (scale bar $2 \mathrm{~nm}$ ). Images recorded at 5 K; (D) Supported single atom alloy PtCu nanoparticle catalysts with about $1 \%$ Pt were found to exhibit high activity and selectivity for butadiene hydrogenation to butenes under mild conditions, demonstrating transferability from the model catalyst to the practical catalyst used under realistic reaction conditions. Adapted from Ref. [21-23,25]. 
stabilization of the Pd atom in the hydrogenation of 1-hexyne selectively to 1-hexene has been reported [22]. Strong bonds to the nitrogen atoms firmly anchor the Pd atoms inside the roughly triangular pores in the stacked, two-dimensional layers of $\mathrm{C}_{3} \mathrm{~N}_{4}$, Fig. 4(b). The Pd atom was found electron deficient, electrons being withdrawn by the coordinating nitrogen atoms. This reaction goes to complete hydrogenation to hexane on $\mathrm{Pd}$ particles. The very different properties of a single Pd atom should be further explored using other stabilizers to potentially converge on common design principles.

\subsection{Single atom alloys}

When metal atoms are deposited onto the surface of another metal, they may become bonded within the surface layer of the host metal, in isolation from each other. These materials are called single-atom alloys (SAAs). They are another new class of atomically dispersed site-isolated metal catalyst. The support ligands are the host metal atoms themselves, and the catalysts in this class display behavior markedly different from that of the afore-mentioned catalysts. Single atom alloys of $\mathrm{Pt}$ or $\mathrm{Pd}$ with $\mathrm{Cu}$ host surfaces, $\mathrm{PtCu}$ and $\mathrm{PdCu}$, are shown to be bifunctional in selective hydrogenation reactions of alkynes and dienes to give alkenes [23-26]. The rate-limiting step at near-ambient temperatures is $\mathrm{H}_{2}$ activation, which is facile on $\mathrm{Pd}$ or Pt atoms, but not on copper surfaces [23-25]. When Pd or Pt atoms are isolated in a single-crystal $\mathrm{Cu}(111)$ surface, $\mathrm{H}_{2}$ dissociation occurs exclusively at the isolated noble metal atom sites, followed by spillover of atomic $\mathrm{H}$ onto the copper metal host, Fig. 4(C) and (D). This weakly bonded $\mathrm{H}$ is selective for the production of alkenes that desorb before further hydrogenation to alkanes can occur-thus the catalyst is selective in a way that conventional metals and alloys are not by virtue of being bifunctional. Furthermore, in 1,3-butadiene hydrogenation, single isolated $\mathrm{Pt}$ atoms in copper activate $\mathrm{H}_{2}$ and induce spillover, without breaking $\mathrm{C}-\mathrm{C}$ bonds, thus preventing 1,3-butadiene decomposition and the surface poisoning that occurs when the surface has higher platinum coverage (an ensemble effect) [25]. Ligand effects can also play a beneficial role in single atom alloy catalysts, with $\mathrm{PtCu}$ catalysts being more resistant to CO poisoning than extended Pt surfaces [26]. Fig. 5 illustrates the activity and selectivity of $\mathrm{PtCu}$ SSA nanoparticles supported on alumina in the selective hydrogenation of 1,3-butadiene [25]. FTIR spectra in the carbonyl range of pre-reduced $\mathrm{Pt}_{0.008} \mathrm{Cu}-\mathrm{SAA}$, $\mathrm{Pt}_{0.39} \mathrm{Cu}$-bimetallic, and $\mathrm{Pt}_{0.1} / \mathrm{Al}_{2} \mathrm{O}_{3}$-monometallic nanoparticles are shown in Fig. 5(D) [26]. Much weaker CO adsorption on Pt atoms was found.

\section{Synthesis of single-atom metal catalysts at high loadings}

A major issue with supported single atom metal catalysts
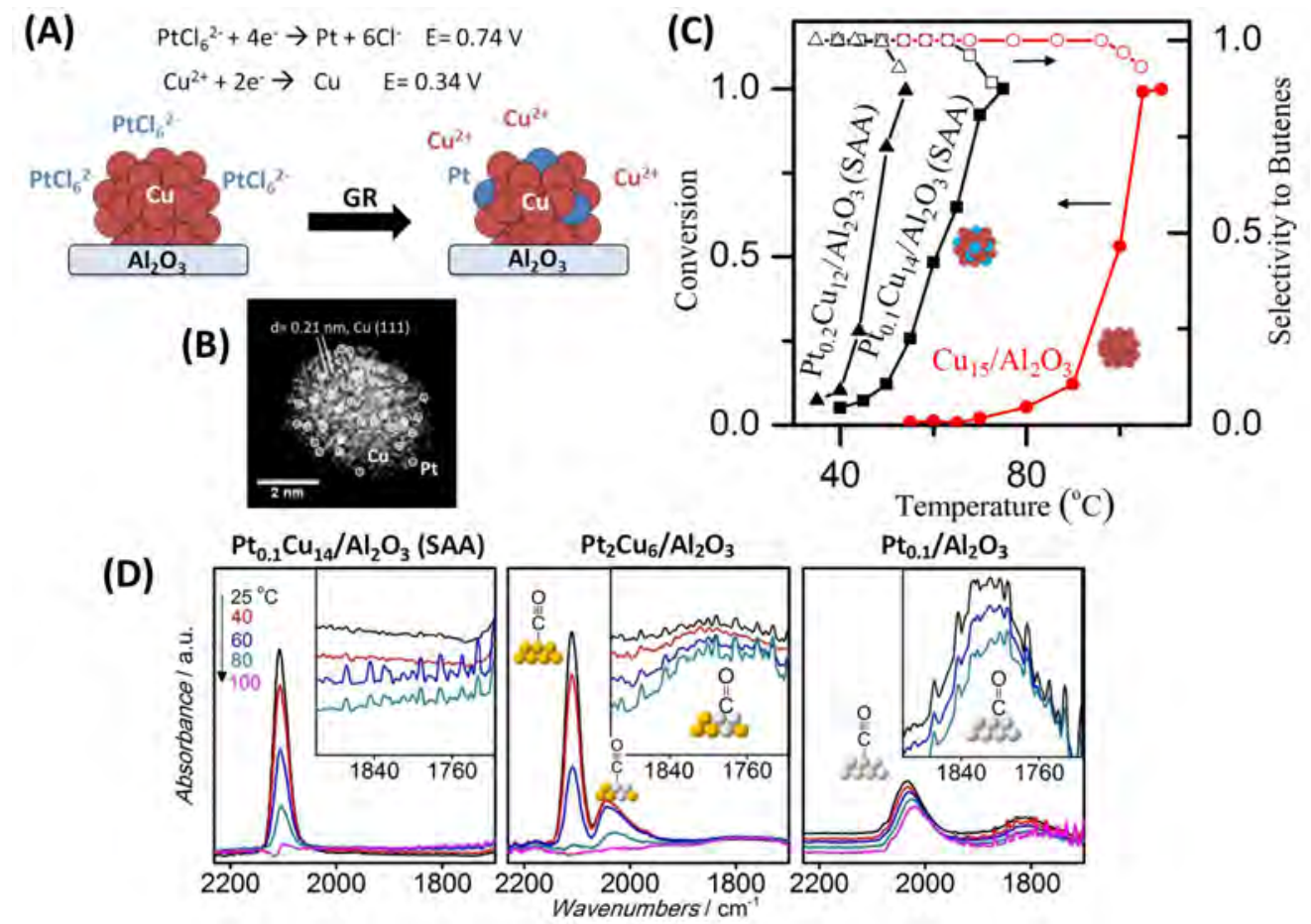

Fig. 5. PtCu-single atom alloy nanoparticles: (A) Galvanic replacement reaction imbeds Pt atoms in a copper nanoparticle surface; (B) aberration-corrected HAADF/STEM image of single atom alloy sample $\mathrm{Pt}_{0.1} \mathrm{Cu}_{14} / \mathrm{Al}_{2} \mathrm{O}_{3}$, showing copper metal particles with isolated $\mathrm{Pt}$ atoms. Isolated Pt atoms are highlighted with circles. The lattice spacing of $\mathrm{Cu}(111)$ is $0.21 \mathrm{~nm}$. (C) Selective hydrogenation of 1,3-butadiene. Hydrogenation shown as a function of temperature for the reaction catalyzed by $\mathrm{Cu}_{15} / \mathrm{Al}_{2} \mathrm{O}_{3}, \mathrm{Pt}_{0.1} \mathrm{Cu}_{14} / \mathrm{Al}_{2} \mathrm{O}_{3}$, and $\mathrm{Pt}_{0.2} \mathrm{Cu}_{12} / \mathrm{Al}_{2} \mathrm{O}_{3} \mathrm{SAA}$ nanoparticles $(1,3-$ butadiene $(1.25 \%)$, $\mathrm{H}_{2}(20 \%)$, and helium (balance); gas hourly space velocity $=1200 \mathrm{~h}^{-1}$ ). (D) FTIR spectra in the carbonyl range of pre-reduced Pt $\mathrm{t}_{0.008} \mathrm{Cu}-\mathrm{SAA}$, $\mathrm{Pt}_{0.39} \mathrm{Cu}$-bimetallic, and $\mathrm{Pt}_{0.1} / \mathrm{Al}_{2} \mathrm{O}_{3}$-monometallic nanoparticles. Adapted from Refs. [25,26]. 
has been their preparation at high metal loadings. To achieve this, one should first understand what are the preferred support sites for metal atom anchoring and then try to maximize them on a given support. Accordingly, the support properties are important in this undertaking. While most of the conventional synthesis methods succeed in preparing metal atoms coordinated with the support, they are typically present along with various size clusters and nanoparticles on the surface. For some reactions, like the WGS and methanol reactions, as described above, this is inconsequential. These reactions proceed on the single $\mathrm{M}-\mathrm{O}_{X^{-}}$sites unaffected by the presence of the nanoparticles. The practical designs are sub-optimal of course, as a lot of precious metal is wasted in these catalysts. However, this is not the case with other reactions, like selective hydrogenation reactions, where the selectivity is metal structure-sensitive. For example, an undesired reaction, i.e. the unselective butadiene hydrogenation to n-butane, is catalyzed by the formation of $\mathrm{Pt}$ atom chains and islands on the $\mathrm{Cu}$ surfaces [25]. It is possible to delay the formation of the undesired $\mathrm{Pt}$ structures by controlling the $\mathrm{Cu}$ particle properties, e.g. the density of step edges at which single Pt (and Pd) atoms preferentially anchor $[23,25]$. In single atom alloys, it is relatively easy to prepare high loadings of the minority metal contained primarily in the surface of the host metal nanoparticles by properly distributing the SAA nanoparticles on various oxide or carbon supports, even exploiting core-shell designs or other such approaches.

An excellent account of the synthesis methods used to date to prepare single atom catalysts on various supports was recently given in a review paper by Liu [27]. These will not be covered here. For low (0.1-0.2 wt.\%) loadings of single metal atoms, Liu, and Zhang and their colleagues at Dalian, show that the anchoring site is a vacant atom site in the support surface, e.g. Pt atom substitutes a $\mathrm{Fe}$ cation in the $\mathrm{Fe}_{2} \mathrm{O}_{3}$ surface [28]. Similarly, an $\mathrm{Au}$ atom substitutes a $\mathrm{Ce}^{4+}$ cation in the $\mathrm{CeO}_{2}$ surface lattice, etc. [29]. The extent of this substitution, whereby the metal atom is in essence a dopant, is limited by the lack of extensive oxide solid solution formation between the transition metals and these oxides. An aliovalent metal atom substituent can also create oxygen vacancies by way of the different oxidation state of the dopant, e.g. two $\mathrm{Au}^{3+}$ in two $\mathrm{Ce}^{4+}$ sites, will create one oxygen vacancy for charge neutrality. This has further repercussions for some oxidation reactions.

$\mathrm{Au}_{1} / \mathrm{Fe}_{2} \mathrm{O}_{3}$ was imaged by Allard et al. [8] at ORNL in 2009, using a catalyst prepared by coprecipitation, containing $5 \mathrm{wt} . \%$ $\mathrm{Au} / \mathrm{Fe}_{2} \mathrm{O}_{3}$ by the World Gold Council (ref. no. 60C), and its leached (by NaCN solution) derivative catalyst, prepared by our group at Tufts [7], which contained $\sim 1.8$ wt.\%Au, mostly as atoms on the surface of the support, and a few gold nanoparticles in the bulk, encapsulated inside the pores of the iron oxide, as shown in Fig. 6(A) and (B) $[7,8]$. This stability of gold atoms on iron oxide, was understood by parallel surface science investigations where stability of $\mathrm{Au}$ adatoms over the uncapped -0 sites on single crystal $\mathrm{Fe}_{3} \mathrm{O}_{4}(111)$ was shown even after annealing at $500{ }^{\circ} \mathrm{C}$ (Fig. 6(C), [30]). The structural evolution of gold in fast heating in situ in the microscope to
$500{ }^{\circ} \mathrm{C}$, is shown in Fig. 6(D) and (E). This was one of the first demonstrations by ac-HAADF/STEM microscopy of a stable (even after $400{ }^{\circ} \mathrm{C}$-air calcination or $\mathrm{H}_{2}$-reduction [7]) single-atom catalyst on an open oxide support. Of course, other techniques had been used prior to these demonstrations by microscopy, including EXAFS and FTIR, to demonstrate isolated metal atoms on supports.

To achieve higher single atom metal loadings, other principles and approaches must be applied. Interestingly, if one makes a high gold or platinum content catalyst by co-precipitation or impregnation on the ceria support and then remove the "extra" gold or platinum from the surface by cyanidation, followed by several washings, and high-temperature calcination, loadings of 0.5-1.0 wt.\% gold are possible $[4,5,7]$. The defect properties of the support control the number of anchoring points. A modified two-step method was used to make single-atom gold on titania, a support that does not disperse the gold, unlike ceria or iron oxide [9]. Accordingly, because titania is photoresponsive, a UV-assisted deposition-precipitation was used to create $\mathrm{Au}(\mathrm{I})-0-\mathrm{Ti}^{3+}$ sites, the $\mathrm{Ti}^{3+}$ stabilized by the anchoring of the $\mathrm{Au}-\mathrm{O}_{x^{-}}$as verified by EPR. After cyanidation to remove the weakly bound gold particles and clusters, the titania contained isolated gold atoms at a loading of $1.2 \mathrm{wt} . \%$, the highest ever reported on this support. The catalyst was as active as the ceria or iron oxide supported $\mathrm{Au}-\mathrm{O}_{x^{-}}$for the WGS reaction, Fig. 1(B). Single-step synthesis methods would be simpler, however, and remain an active area of research in the current literature.

Dopant and shape effects. The first demonstration that high-temperature annealed ceria is not an effective support of metal atoms $(\mathrm{Au}, \mathrm{Cu}, \mathrm{Pt}, \ldots)$ came from our work on $\mathrm{Cu}$ and $\mathrm{Au} / \mathrm{CeO}_{2}[1,2,4,5]$ and of course by the automotive exhaust literature on $\mathrm{Pt}-\mathrm{O}_{x}$-Ce catalytic sites that preceded ours [3]. It was realized that an oxygen defect-rich ceria was needed to atomically disperse the metals, and achieve high metal loadings. One approach to achieve this is to dope the ceria with trivalent lanthanide ions, e.g. $\mathrm{La}^{3+}$ or $\mathrm{Gd}^{3+}$, two of which create an oxygen vacancy in ceria for charge neutrality. The doped ceria is much more resistant to sintering upon high-temperature annealing in air, preserving $7 \mathrm{~nm}$-avg. particle size after $600{ }^{\circ} \mathrm{C}$ calcination. $\mathrm{Au}^{3+}$ doped in ceria has a similar effect [4,5]. The creation of oxygen vacancies was considered important in stabilizing $\mathrm{Au}$ atoms on ceria for the WGS and SRM reactions discussed above. A potential shape effect of ceria was next investigated and reported for the first time in 2008 [6]. Indeed, different facets of ceria, i.e. $\{100\}$ facets in single crystal ceria nanocubes or $\{110\}$ and $\{111\}$ facets in ceria nanorods and nanooctahedra, have very different number of anchoring sites for gold, thereby proving the shape effect. The shape effect was shown to be "indirect" in the WGS and SRM reactions, as the intrinsic activity of the single $\mathrm{Au}-\mathrm{O}_{x^{-}}$ active site was the same on the different shapes; and was the same on different supports, like $\mathrm{ZnO}, \mathrm{FeO}_{x}$, and other supports, as discussed above. But the design principles from this work are clear: a nanosized, defect-rich ceria, with a preponderance of $\{111\}$ planes is desirable for the creation of many anchoring 

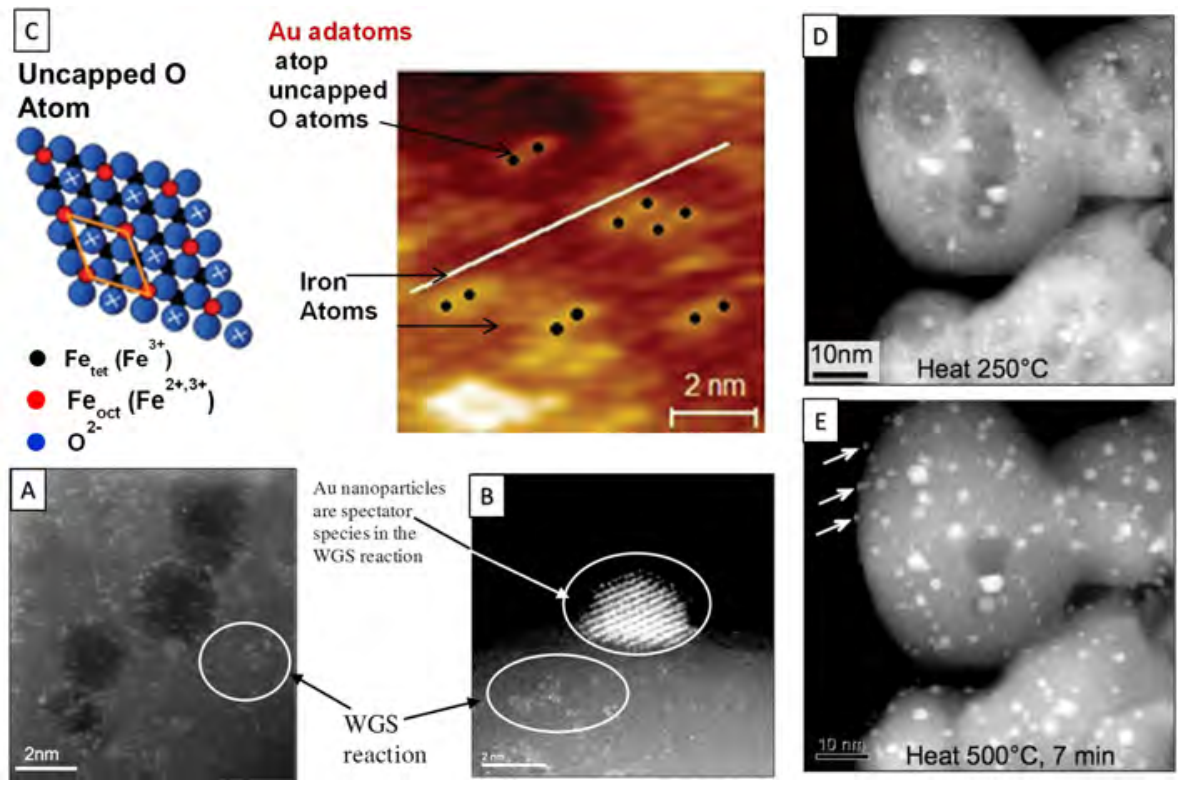

Fig. 6. Direct imaging of $\mathrm{Au} / \mathrm{FeO}_{\mathrm{x}}$ catalysts and their evolution in different heat treatments. (A) ac- $\mathrm{HAADF} / \mathrm{STEM}$ images of the $\mathrm{Au} / \mathrm{Fe}_{2} \mathrm{O}_{3}$ catalyst supplied by the World Gold Council, containing 1.8 wt.\% Au as atoms in the $5 \mathrm{wt} . \%$ Au parent sample, comprising both particles and atoms; (B) and in the cyanide-leached sample both after air-calcination at $400{ }^{\circ} \mathrm{C}$; (C) Model catalyst studies revealed that Au adatoms are strongly bound to the uncapped $\mathrm{O}$ atoms in the 3 -fold hollow of the $\mathrm{Fe}(\mathrm{III})$ terminated $\mathrm{Fe}_{3} \mathrm{O}_{4}(111)$ surfaces [30]. They are stable after $500{ }^{\circ} \mathrm{C}$ annealing, which elucidates the stability of single gold atoms on the real catalyst; (D, E) In fast in-situ heating experiments in the microscope, migration of Au atoms to the external surface of $\mathrm{Fe}_{2} \mathrm{O}_{3}$ particles, growth of Au nanoclusters and particles, and collapse of internal bulk pores of the iron oxide and redistribution of gold nanoclusters following thermal anneal to $500{ }^{\circ} \mathrm{C}$ was documented. A strong interaction with the $\mathrm{FeO}_{x}$ support prevents further growth of gold nanoparticles up to $700^{\circ} \mathrm{C}$ [8]. Adapted from Ref. [8,30,31].

sites for $\mathrm{Au}, \mathrm{Pt}, \mathrm{Cu}, \mathrm{Ni}$, or another metal. This early work did not specify whether the metal atoms were anchored on multiple defect sites of ceria; i.e. in a missing cerium atom; or over an oxygen vacancy or an uncoordinated oxygen, etc. DFT calculations have been evolving over the last ten years using such anchoring sites, still without answering this question uniquely. Complicating the matter of course, is the more difficult question to answer both experimentally and computationally; namely, which one of all these sites is stabilized under dynamic reaction conditions. This knowledge is the overarching goal in any catalyst design.

The combination of atomic-resolution surface science and microscopy is powerful in answering some of the above questions. From a series of papers, focusing on the $\mathrm{Au} / \mathrm{FeO}_{x}$ catalyst for the WGS reaction, came the first images of $\mathrm{Au}$ atoms on iron oxide as the unequivocal sites for this reaction, using aberration-corrected HAADF/STEM and E-TEM [8], as stated above, Fig. 6(A) and (B). Interestingly, a significant parallel investigation of $\mathrm{Au} / \mathrm{Fe}_{3} \mathrm{O}_{4}$ (111) made by atomic-resolution Scanning Tunneling Microscopy (STM) in vacuum provided evidence of the preferential site of isolated $\mathrm{Au}$ atoms in this surface. These are the 3-fold hollow sites of Fe (III) where the $\mathrm{Au}$ atom is found over the uncapped $\mathrm{O}-$ in the Fe(III)-terminated $\mathrm{Fe}_{3} \mathrm{O}_{4}$ (111) surface, as depicted in Fig. 6(C) [30]. The distance between the isolated $\mathrm{Au}$ atoms is $0.52 \mathrm{~nm}$. The $\mathrm{Au}$ atom adsorbs CO linearly and is slightly positively charged. In subsequent reports, this site was found to have the right properties for the WGS reaction as the $-\mathrm{OH}$ and hydrogen-bonded $\mathrm{H}_{2} \mathrm{O}$ are preferentially adsorbed on the vicinal Fe cations, and DFT calculations show such a site to have the right properties for the WGS reaction [31].

Single-step synthesis methods. Active and inert oxides, carbon-based supports, metal surfaces and other supports have been used to atomically disperse metals. It would be desirable from a practical viewpoint to develop one-pot synthesis methods that achieve high single metal atom loadings in the various support surfaces. The preparation of the single atom alloys discussed above provides such a method through the galvanic replacement reaction to add noble metal atoms (Pt, $\mathrm{Pd}$, $\mathrm{Au}, . .$.$) on a less noble metal matrix (\mathrm{Cu}, \mathrm{Ni}, . .$.$) by spontaneously$ removing an equal amount of $\mathrm{Cu}$ or $\mathrm{Ni}$ atoms as cations in the solution. When galvanic replacement is not appropriate, sequential deposition of the minority metal on the host one has worked for many metal pairs.

For the selective hydrochlorination of acetylene to VCM, the Hutchings group used a single-step method, involving impregnation with $\mathrm{HAuCl}_{4}$ dissolved in aqua regia, to prepare 1 wt.\% Au supported on carbon powders, almost exclusively as isolated $\mathrm{Au}(\mathrm{III})$ cations [21]. During reaction, $\mathrm{Au}(\mathrm{Cl})_{\mathrm{x}^{-}}$species comprising both $\mathrm{Au}(\mathrm{III})$ and $\mathrm{Au}(\mathrm{I})$ would form, activating the reactants. Other carbon supports, such as extrudates, are successfully employed as carriers of the active gold atom species in the commercial catalyst.

Yang et al. [11,12] have demonstrated that $\mathrm{Na}, \mathrm{K}$ ions can stabilize mononuclear $\mathrm{Au}$ or Pt through -O bonds and provide hydroxyls to the $\mathrm{Au}$ or Pt-centered oxo cluster. As mentioned above, the surrounding alkali cations are also stabilized in this way. The $\mathrm{Au}, \mathrm{Pt}-\mathrm{O}(\mathrm{OH})_{x}$-Na, K cluster is prepared by single-step methods involving co-incipient wetness impregnation using a strong base $(\mathrm{NaOH}, \mathrm{KOH})$ and the precursor $\mathrm{Au}$ or Pt reagents; 
or by sequential incipient wetness impregnation of the metal precursor, and solid state base impregnation, the latter used when the support is silica-based to avoid its partial dissolution. This method was developed to achieve single atom preparations of $\mathrm{Au}$ or Pt on inert supports, such as zeolites, silica, alumina, carbon nanotubes, etc. where other methods fail to produce them as atomically dispersed species due to the lack of readily reducible surface oxygen species. But, it can also be used with "active" supports, adding more atomic gold or platinum on their surfaces and increasing the active site loading this way. Anchored on any high-surface area support, loadings may exceed 1 wt.\% $\mathrm{Au}$ or $\mathrm{Pt}$, exclusively as mononuclear species. This method may be extended to other metals and in the investigation of other reaction systems that may be catalyzed on single metal atoms.

\section{Active site stability and structural evolution during reaction}

While several methods now exist to prepare single metal atoms on various supports, it is well known and should be anticipated that the reaction conditions, or even simple heating protocols in different gases will alter the single-site catalyst. The evolution of structures during reaction is of great interest in our efforts to design more robust catalysts. For example, while ceria is one of the best oxide supports for atomically dispersing metals, it cannot preserve the $\mathrm{M}-\mathrm{O}_{x^{-}}$species under highly reducing environments, or very high temperatures. Annealed ceria with few surface defects is not a good support because it lacks enough anchoring points to atomically disperse and stabilize the active metal species [5]. From recent surface science studies, we have learned that $\mathrm{Pt}$ anchors as $\mathrm{Pt}(\mathrm{II})-\mathrm{O}_{x^{-}}$on the step edges of $\mathrm{CeO}_{2}$ (111), but as $\mathrm{Pt}(0)$ over oxygen vacancies in ceria, long considered the important metal ion anchoring sites [32]. This needs to be investigated and documented in detail for practical ceria-based catalysts, and proper designs proposed for stable catalyst preparations.

What structure eventually stabilizes under working conditions depends on thermodynamics and reaction kinetics. This dynamic evolution of the active site must be elucidated and understood before one develops practical catalyst designs. At the fundamental level, it is important to understand the evolution through the different transition states, while the evolution with time-on-stream is important for the practical catalyst development. Considering the water-gas shift reaction as an example, a very reducing environment destabilizes the $\mathrm{Au}$ or Pt single cation species coordinated on the ceria surfaces, and metal clusters and nanoparticles are formed, with concomitant deactivation. Deng et al. [33] have shown this by using in situ EXAFS of the $\mathrm{Au}-\mathrm{O}_{x}-\mathrm{Ce}$ catalysts whereby at different temperatures the $\mathrm{Au}-\mathrm{Au}$ coordination number increased. The deactivation may be prevented, if $\mathrm{O}_{2}$-assisted WGS reaction is used, keeping the metal atom oxidized, as was shown for $\mathrm{Au} / \mathrm{CeO}_{2}$ [34]. It has also been realized that regeneration of the active gold atomic sites is possible by re-oxidation in air at $\geq 400{ }^{\circ} \mathrm{C}$. If prepared by co-precipitation, the bulk of the support serves as a reservoir of metal atoms which can diffuse to the surface and coordinate as additional atomically bound active species. The atomic Pt- $\mathrm{O}_{x}$-Ce site in the automotive exhaust catalyst is preserved by the very fast redox between fuel-rich and fuel-lean operation to keep the catalyst running at the desired stoichiometric conditions [35].

Atomically dispersed $\mathrm{Au}$ on $\mathrm{FeO}_{x}$ supports show a remarkable stability in heat treatments up to $500{ }^{\circ} \mathrm{C}$, as shown in Fig. 6 both as model catalysts, Fig. 6(C), and as nanoparticles, Fig. 6(A), (B), (D), with a high content of atoms and sub-nm clusters, resisting sintering. Thus, growth of gold particles and deactivation at working WGS conditions may be largely prevented on this type catalyst. The evolution of Au structures as a function of heating was followed by aberration-corrected microscopy for the $\mathrm{Au} / \mathrm{FeO}_{x}$ catalyst, as shown in Fig. 6(D) and (E). Environmental microscopy (E-TEM) now permits direct observation of catalyst structure, atomically resolved, and its evolution under reaction conditions.

As mentioned earlier, the surge in investigations of atomically dispersed supported metal catalysts is enabled by the recent advances of atomic resolution microscopy techniques, most notably STM, STEM, and E-TEM [36,37]. Key advances in the development of detection as well as in their operation under in situ or even in operando conditions, makes it now possible to avoid beam damage, and allow real time observation of catalyst formation and activity on the ms time scale. Other in operando techniques, include spectroscopies such as synchrotron-based XAFS, and vibrational spectroscopies such as IR and Raman, all enabling an unprecedented mechanistic insight into the correlation of structure and function as they allow the observation of catalysts switching states in real time. Moreover, advances in STM are particularly well suited for studies of single site model catalysts and offer the most amenable systems with which to unambiguously correlate the atomic scale structure of active sites with their chemistry. Recent advances in scanning probe technology, for example with non-contact AFM allowing Angstrom-level resolution of molecules and chemical intermediates, enable an unprecedented ability to characterize adsorption and reaction. This information is crucial for informing accurate theoretical models that in turn can offer insights in the mechanistic understanding and inform the design of practical catalysts, as shown by the examples of $\mathrm{Pt} / \mathrm{Cu}(111)$ single atom alloys (Fig. 4(C), (D) and Fig. 5) and the $\mathrm{Au} / \mathrm{Fe}_{3} \mathrm{O}_{4}(111)$ single crystal system, Fig. 6(C). Finally, high-pressure STM offers a means to follow the evolution of catalytically relevant surfaces as the pressure gap is bridged. Theory has also advanced, allowing us to evaluate the interfacial interactions with more precision, providing an essential role in evaluating and interpreting experimental data.

\section{Conclusions}

In conclusion, a lot of new ground has been broken with the advances in the synthesis and characterization methods to enable us to design better catalysts in general, and robust 
single atom isolated catalysts in particular, for reactions catalyzed by such active sites. This promises that all three key catalyst properties; namely, activity, selectivity, and stability will be possible to optimize at the same time.

\section{Acknowledgment}

I am grateful to the many generations of students and postdocs who have contributed to the advances of single atom catalysis research in our group over the last two decades, especially to Wei Liu, Ljiljana Kundakovic, Qi Fu, Weiling Deng, Svetlana Kudriavtseva, Danny Pierre, Yanping Zhai, Rui Si, Peter Kracke, Zheng Zhou, Nan Yi, Matt Boucher, Chongyang Wang, Branko Zugic, Ming Yang, Junjun Shan, and Jilei Liu, whose many contributions are only partly covered in this paper. I also acknowledge the valuable collaborations of colleagues Howard Saltsburg(d.), Terry Haas, and Charlie Sykes at Tufts, George Flynn and Richard Osgood at Columbia, Manos Mavrikakis at Wisconsin, Larry Allard at ORNL, and Sungsik Lee at ANL. The financial support of the work by the U.S. Department of Energy (DOE), Office of Science, Basic Energy Sciences (BES), under Awards Grant Number DE-FG02-05ER15730, is gratefully acknowledged.

\section{References}

[1] W. Liu, M. Flytzani-Stephanopoulos, J. Catal., Part I, 1995, 153,
304-316.

[2] W. Liu, M. Flytzani-Stephanopoulos, J. Catal., Part II, 1995, 153, 317-332.

[3] L. L. Murrell, S. J. Tauster, D. R. Anderson, Stud. Surf. Sci. Catal. 1991, 71, 275-289.

[4] Q. Fu, H. Saltsburg, M. Flytzani-Stephanopoulos, Science, 2003, 301, 935-938.

[5] Q. Fu, W. Deng, H. Saltsburg, M. Flytzani-Stephanopoulos, Appl. Catal. B, 2005, 56, 57-68.

[6] R. Si, M. Flytzani-Stephanopoulos, Angew. Chem. Int. Ed., 2008, 47, 2884-2887.

[7] W. Deng, C. Carpenter, N. Yi, M. Flytzani-Stephanopoulos, Top. Catal., 2007, 44, 199-208.

[8] L. F. Allard, A. Borisovich, W. Deng, R. Si, M. Flytzani-Stephanopoulos, S. H. Overbury, J. Electron Microsc., 2009, 58, 199-212.

[9] M. Yang, L. F. Allard, M. Flytzani-Stephanopoulos, J. Am. Chem. Soc., 2013, 135, 3768-3771.

[10] Y. Zhai, D. Pierre, R. Si, W. Deng, P. Ferrin, A. U. Nilekar, G. Peng, J. A. Herron, D. C. Bell, H. Saltsburg, M. Mavrikakis, M. Flytzani-Stephanopoulos, Science, 2010, 329, 1633-1636.

[11] M. Yang, S. Li, Y. Wang, J. A. Herron, Y. Xu, M. Mavrikakis, L. F. Allard, S. Lee, J. Huang, M. Flytzani-Stephanopoulos, Science, 2014, 346, 1498-1501.

[12] M. Yang, J. Liu, S. Lee, B. Zugic, J. Huang, L. F. Allard, M. Flytzani-Stephanopoulos, J. Am. Chem. Soc., 2015, 137, 3470-3473.

[13] B. Zugic, D. C. Bell, M. Flytzani-Stephanopoulos, Appl. Catal. B, 2014, 144, 243-251.

\section{Graphical Abstract}

Chin. J. Catal., 2017, 38: 1432-1442 doi: 10.1016/S1872-2067(17)62886-9

\section{Supported metal catalysts at the single-atom limit - A viewpoint}

Maria Flytzani-Stephanopoulos *

Tufts University, USA
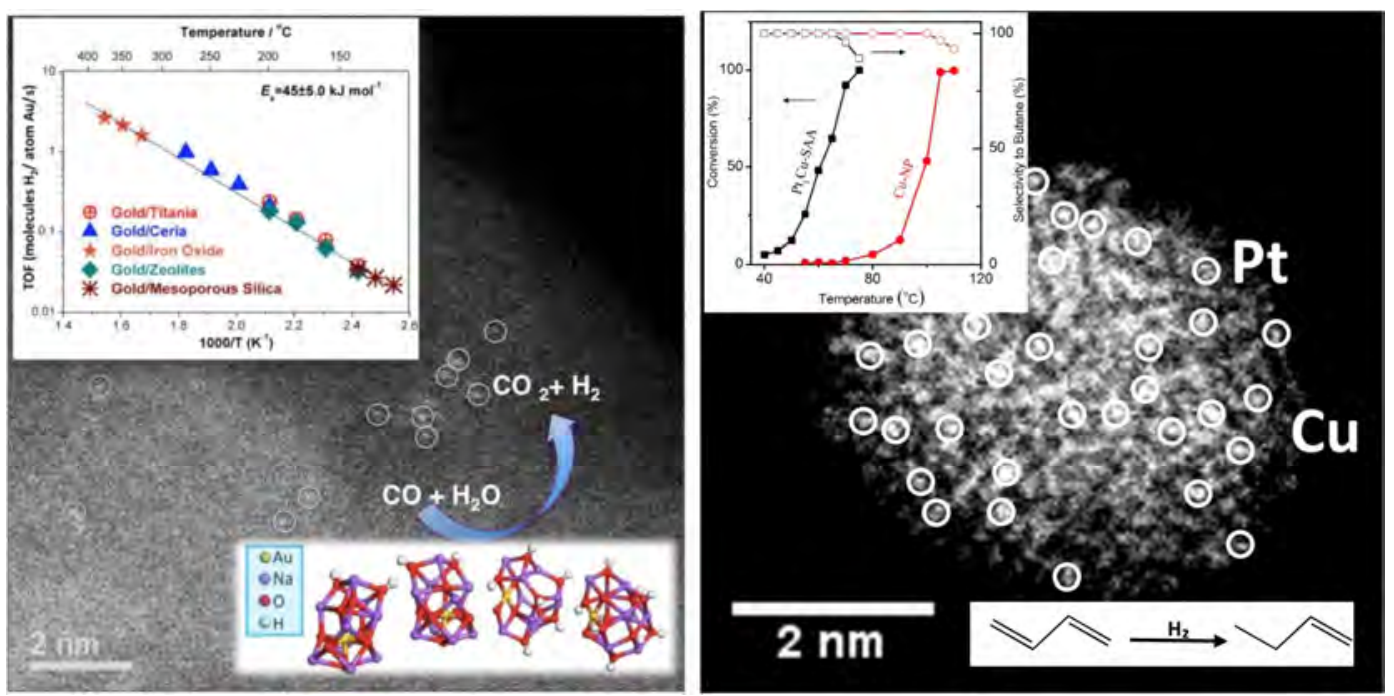

Single metal atoms supported on oxides catalyze the water-gas shift reaction. Single Atom Alloys (SAAs) comprise single metal atoms embedded in another metal surface. Shown here is the selective hydrogenation of butadiene to butene over PtCu SAAs at near ambient temperatures. 
[14] N. Yi, R. Si, H. Saltsburg, M. Flytzani-Stephanopoulos, Energy Environ. Sci., 2010, 3, 831-837.

[15] N. Yi, R. Si, H. Saltsburg, M. Flytzani-Stephanopoulos, Appl. Catal. $B, 95,87-92$.

[16] N. Yi, M. B. Boucher, F. Gittleson, B. Zugic, H. Saltsburg, M. Flytzani-Stephanopoulos, J. Phys. Chem. C, 2011, 115, 1261-1268.

[17] C. Wang, M. Boucher, M. Yang, H. Saltsburg, M. Flytzani-Stephanopoulos, Appl. Catal. B, 2014, 154, 142-152.

[18] B. Xu, X. Liu, J. Haubrich, R. Madix, C. Friend, Angew. Chem. Int. Ed., 2009, 48, 4206-4209.

[19] A. Wittstock, V. Zielasek, J. Biener, C. M. Friend, M. Bäumer, Science, 2010, 327, 319-322.

[20] C. Wang, G. Garbarino, L. F. Allard, F. Wilson, G. Busca, M. Flytzani-Stephanopoulos, ACS Catal., 2016, 6, 210-218.

[21] G. Malta, S. A. Kondrat, S. J. Freakley, C. J. Davies, L. Lu, S. Dawson, A. Thetford, E. K. Gibson, D. J. Morgan, W. Jones, P. P. Wells, P. Johnston, C. R. A. Catlow, C. J. Kiely, G. J. Hutchings, Science, 2017, 355, 1399-1403.

[22] G. Vilé, D. Albani, M. Nachtegaal, Z. Chen, D. Dontsova, M. Antonietti, N. López, J. Pérez-Ramírez, Angew. Chem. Int. Ed., 2015, 54, 11265-11269.

[23] G. Kyriakou, M. B. Boucher, A. D. Jewell, E. A. Lewis, T. J. Lawton, A. E. Baber, H. L. Tierney, M. Flytzani-Stephanopoulos, E. C. H. Sykes, Science, 2012, 335, 1209-1212.

[24] M. B. Boucher, B. Zugic, G. Cladaras, J. Kammert, M. D. Marcinkowski, T. J. Lawton, E. C. H. Sykes, M. Flytzani-Stephanopoulos, Phys. Chem. Chem. Phys., 2013, 15, 12187-12196.

[25] F. R. Lucci, M. P. Marcinkowski, C. E. H. Sykes, J. Liu, M. Yang, M.
Flytzani-Stephanopoulos, L. F. Allard, Nat. Commun., 2015, 6, 8550.

[26] J. Liu, F. R. Lucci, M. Yang, S. Lee, M. D. Marcinkowski, A. J. Therrien, C. T. Williams, E. C. H. Sykes, M. Flytzani-Stephanopoulos, J. Am. Chem. Soc., 2016, 138, 6396-6399.

[27] J. Y. Liu, ACS Catal., 2017, 7, 34-59.

[28] B. T. Qiao, A. Q. Wang, X. F. Yang, L. F. Allard, Z. Jiang, Y. T. Cui, J. Y. Liu, J. Li, T. Zhang, Nat. Chem., 2011, 3, 634-641.

[29] B. T. Qiao, J. X. Liu, Y. G. Wang, Q. Q. Lin, X. Y. Liu, A. Q. Wang, J. Li, T. Zhang, J. Y. Liu, ACS Catal., 2015, 5, 6249-6254.

[30] K. T. Rim, D. Eom, L. Liu, E. Stolyarova, J. M. Raitano, S. W. Chan, M. Flytzani-Stephanopoulos, G. W. Flynn, J. Phys. Chem. C, 2009, 113, 10198-10205.

[31] K. T. Rim, D. Eom, S. W. Chan, M. Flytzani-Stephanopoulos, G. W. Flynn, X. D. Wen, E. R. Batista, J. Am. Chem. Soc., 2012, 134, 18979-18985.

[32] F. Dvořák, M. Farnesi Camellone, A. Tovt, N. D. Tran, F. R. Negreiros, M. Vorokhta, T. Skála, I. Matolínová, J. Mysliveček, V. Matolín, S. Fabris, Nat. Commun., 2016, 7, 10801.

[33] W. L. Deng, A. I. Frenkel, R. Si, M. Flytzani-Stephanopoulos, J. Phys. Chem. C, 2008, 112, 12834-12840.

[34] W. Deng, M. Flytzani-Stephanopoulos, Angew. Chem. Int. Ed., 2006 45, 2285-2289.

[35] M. Hatanaka, N. Takahashi, T. Tanabe, Y. Nagai, K. Dohnae, Y. Aoki, T. Yoshida, H. Shinjoh, Appl. Catal. B, 2010, 99, 336-342.

[36] M. Flytzani-Stephanopoulos, B. C. Gates, Annu. Rev. Chem. Biomol. Eng., 2012,3, 545-574.

[37] J. M. Thomas, Proc. R. Soc. A, 2017, 473, 20160714.

\title{
视角: 单原子尺度的负载型金属催化剂
}

\author{
Maria Flytzani-Stephanopoulos* \\ 塔夫茨大学化学与生物工程系, 梅德福, 马萨诸塞, 美国
}

摘要: 综述了负载型单原子催化剂设计的最新进展, 以及负载型单原子催化剂在多种反应, 如低温水汽变换、甲醇蒸汽重 整、选择性乙醇脱氢、炔烃和二烯烃的选择性加氢等反应中的应用. 研究活性金属原子位的固有活性和选择性, 并与相应 的金属纳米颗粒和次纳米簇的性质相比较是非常重要的. 同时, 理解在不同反应环境下稳定的活性金属原子位的组成, 并 最大化其负载量可使我们设计出适合工业应用的强健催化剂. 在实际工作中, 应将催化剂活性和稳定性研究相结合, 尽可 能遵循活性位随催化剂实时处理条件的变化规律. 原子尺度的先进表征方法至关重要, 可用于指导设计新催化剂.

关键词: 单原子合金; 金; 钯; 负载型单原子催化剂; 水汽变换; 甲醇蒸汽重整; 乙醇脱氢; 丁二烯加氢

收稿日期: 2017-06-01. 接受日期: 2017-07-09. 出版日期: 2017-09-05.

*通讯联系人. 电子信箱: maria.flytzani-stephanopoulos@tufts.edu

本文的英文电子版由Elsevier出版社在ScienceDirect上出版(http://www.sciencedirect.com/science/journal/18722067). 